\title{
Nietzsche e Paul Rée: Acerca da existência de impulsos altruístas
}

\author{
Clademir Luís Araldi*
}

\begin{abstract}
Resumo: Investigaremos a discordância entre Nietzsche e Paul Rée no que tange à existência de impulsos altruístas no ser humano. Paul Rée, em A origem dos sentimentos morais (der Ursprung der moralischen Empfindugen), afirma existirem no homem tanto impulsos egoístas quanto altruístas. A partir da teoria da evolução de Darwin, ele desenvolve uma psicologia moral evolucionista, enfatizando o caráter naturalista das atitudes altruístas. Analisaremos as críticas de Nietzsche ao modo altruísta de valorar, desde Humano, demasiado humano, tendo em vista a discussão que ele trava com Paul Rée acerca do estatuto do hábito, dos costumes e dos motivos das ações. $\mathrm{O}$ novo modo de considerar o prazer, especialmente na intensificação do sentimento de poder, marca uma nova orientação acerca da origem e desenvolvimento dos sentimentos morais, em que o egoísmo ocupa um lugar central. Palavras-Chave: impulsos - egoísmo - altruísmo - prazer sentimentos - moral
\end{abstract}

\section{Paul Rée, Darwin e o altruísmo}

A descrição e a valoração da existência de impulsos altruístas na obra de P. Rée A origem dos sentimentos morais (Der Ursprung der moralischen Empfindungen, 1877) estão fortemente ligadas à teoria da evolução de Darwin e à ética da compaixão de Schopenhauer. Rée pretende, desse modo, naturalizar a compaixão não-egoísta e a-histórica de Schopenhauer, ao mesmo tempo que pretende aplicar

\footnotetext{
* Professor da Universidade Federal de Pelotas (UFPel), Brasil.

Correio eletrônico: clademir.araldi@gmail.com
}

Cad. Nietzsche, Guarulhos/Porto Seguro, v.37, n.1, p. 71-87, 2016. | 71 
Araldi, C. L.

os resultados da teoria de Darwin para o campo moral ${ }^{\mathbf{1}}$. Como ele pretende efetivar isso?

Para o escopo deste artigo, basta mostrar em que sentido Rée se apropria da teoria científica de Darwin. No início de $A$ origem dos sentimentos morais o pensador judeu-pomerano atribui a Lamarck e a Darwin o mérito de remeter "os fenômenos morais a causas naturais". Essa explanação naturalista é resumida na seguinte frase: "Os animais superiores desenvolveram-se mediante seleção natural a partir dos animais inferiores; assim sendo, os seres humanos provieram dos macacos"2. Sirvo-me aqui da análise de André Luís M. Itaparica, de que as investigações de Rée sobre a moralidade seguem em larga medida, as teses que Darwin apresentou em The descent of man (1871). ${ }^{3}$ Importante é notar que a ênfase da história natural de Rée está na gênese e no desenvolvimento do altruísmo. Nesse sentido, o "moralista darwiniano"4, logo a seguir, colocará o foco na distinção entre 1) o impulso egoísta (der egoistische Trieb) e 2) o impulso não-egoísta (der unegoistische Trieb). É uma distinção bem schopenhaueriana! O primeiro impulso permite a cada ser

1 Cf. SMALL, R. Translator'siIntroduction. In. Basic writtings. Illinois: University of Illinois Press, 2003, p. XXV.

2 RÉE, P. Basic writings. Translated and edited by Robin Small. Urbana, Chicago: University of Illinois Press, 2003, p. 92.

3 ITAPARICA, A. L. Nietzsche e P. Rée. "O projeto de naturalização da moral em Humano, demasiado Humano". Pelotas, Dissertatio 38, 2013, p. 61.

4. Emmanuel Salanskis compreende Paul Rée e Nietzsche como "moralistes darwiniens", tendo em vista que ambos procuraram nessa época aplicar os resultados da teoria da evolução de Darwin no campo da moral. O que caracteriza o projeto de P. Rée, segundo Salanskis, é a tentativa de unir uma tradição moral (literária) com uma teoria científica, no caso, a teoria da evolução de Darwin. Cf. SALANSKIS, E. "Moralistes darwiniens: les psychologies évolutionnistes de Nietzsche et Paul Rée”. Nietzsche-Studien, vol. 42, Berlim: de Gruyter, 2013, p. 46. Consideramos relevante o modo como Salanskis trata da influência filosófica de Paul Rée em Nietzsche, na época de Humano, demasiado humano, à medida que permitiu a construção de uma psicologia inspirada tanto nos moralistas franceses quanto no evolucionismo darwiniano. Sem dúvida, Rée se concentra mais neste projeto delimitado de naturalização da moral, enquanto Nietzsche se preocupa em avançar em suas abordagens psicológicas, recorrendo a outras fontes filosóficas, históricas e literárias.

72 Cad. Nietzsche, Guarulhos/Porto Seguro, v.37, n.1, p. 71-87, 2016. 
humano preservar-se, bem como satisfazer seu instinto sexual e sua vaidade (esse último traço é reforçado nas análises de Rée); o segundo impulso diz respeito à compaixão e à benevolência ${ }^{5}$. Da perspectiva do agente, o bem de um outro ser humano é o fim último de sua ação ${ }^{6}$. Schopenhauer valorizava a teoria da evolução (teleológica) de Lamarck em sua ética da compaixão. Mas ele teria ficado a meio do caminho, por não conseguir explicar de modo satisfatório a origem das ações altruístas, remetendo-a a uma metafísica da substância (da Vontade una, na multiplicidade de seus fenômenos). Rée expõe brevemente como outros filósofos explicaram a compaixão. Hume (a quem abordaremos no ponto 2) avança em relação a Hutcheson, mas não explica de modo satisfatório a existência da benevolência (apenas a deriva da constituição original de nosso temperamento).

É Darwin quem fornece uma explanação naturalista satisfatória da gênese das ações não-egoístas. Animal gregário, o homem desenvolveu capacidades intelectuais e aprimorou seus instintos sociais. A sociabilidade, da qual nasceu o sentimento (paixão) da simpatia, é própria de espécies animais. A moralidade humana teria sempre evoluído desses instintos de rebanho (algo tão difícil para Nietzsche admitir), da linguagem, da memória e dos costumes deles

5 Christopher Janaway constata uma dificuldade na argumentação de Paul Rée: se tanto os impulsos altruístas quanto os egoístas são inatos no ser humano, o que garante que o altruísmo se torne preponderante, tendo em vista que os impulsos egoístas são naturalmente mais fortes? Assim Janaway formula o problema: "If egoism is dominant, how is it possible to act in the interest of others or to have the unegoistic feelings or traits of character?" JANAWAY, Christopher. Beyond selflessness: reading Nietzsche’s Genealogy. New York: Oxford University Press, 2007, p. 75. Paul Rée recorre a Darwin para assegurar que as ações e atitudes altruístas ocorrem naturalmente. Assim sendo, Rée conseguiria explicar como a moral surgiu, a saber, porque sentimentos positivos foram associados a esses comportamentos naturais altruístas. Nietzsche passa a discordar de Rée em relação ao caráter naturalista dos instintos sociais. Importante é notar aqui a dificuldade de Rée em provar que através da cultura e das motivações individuais, o egó́smo passou a ser censurado, à medida que sentimentos negativos foram associados a ele. Nessa origem utilitarista da moral, bom não é um valor intrínseco. Assim, não poderia haver uma justificação naturalista coerente da superioridade (e exclusividade) do modo altruísta de valorar. Sentimentos positivos também podem ser associados ao egoísmo.

6 RÉE, P. Basic writings. Op. cit., p. 89. 
Araldi, C. L.

decorrentes. Assim como Schopenhauer, Rée afirma que ações nãoegoístas podem ser empiricamente constatáveis. Dos muitos exemplos diários e historicamente constatáveis, ele conclui: “Assim, há um interesse não egoísta no destino dos outros, que pode ser chamado de compaixão, benevolência ou amor ao próximo"" . Ele recorre a Darwin, para mostrar que as ações não egoístas têm origem em nossos antepassados, os primatas:

Assim como muitas espécies animais, como as abelhas e as formigas, nossos ancestrais, os primatas, possuíam um instinto social. [...] $\mathrm{O}$ instinto social surge como uma extensão do instinto parental, e é então mantido e fortalecido por seleção natural, ou seja, pelo fato de que as espécies animais, cujos membros estavam mais fortemente ligados por instintos sociais triunfaram sobre outras espécies, e assim se conservaram"8.

O amor da mãe por seu filhinho é o exemplo mais elucidativo que Rée utiliza para mostrar que ações altruístas existem: "uma mãe que vê seu filho sofrer não sente dor porque imagina que o filho está sofrendo [...], mas é justamente o fato de que o filho sofre que a faz sentir dor"9. Contra Helvétius (e Nietzsche), Rée afirma a efetividade de ações não-egoístas: "o que me incomoda é que o outro sofra"; a dor que sinto pelo sofrimento do outro e os esforços que faço para aliviá-lo não são uma mera representação de minha dor, ou das tentativas para aliviá-la (como no caso da compaixão egoísta). É preciso, desse modo, explicitar o motivo dessas ações (o sofrimento do outro), em ligação com o sentimento de prazer e desprazer, com o caráter do agente e com os costumes sociais. Temos de retornar a Hume.

7 RÉE, P. Basic writings. Op. cit., p. 91.

8 RÉE, P. Basic writings. Op. cit., p. 92.

9 RÉE, P. Basic writings. Op. cit., p. 90.

74|Cad. Nietzsche, Guarulhos/Porto Seguro, v.37, n.1, p. 71-87, 2016. 


\section{Paul Rée, Hume e Schopenhauer: a naturalização do altruísmo}

Segundo Hume, o embate próprio no mundo humano se daria entre paixões fortes e fracas, calmas e violentas, desvinculado de qualquer faculdade extrínseca à Natureza Humana (sentimentos morais estão alojados na Natureza Humana). O necessitarismo aplicado às ações permite explicar o modo como os objetos nos afetam, a partir das impressões que resultam imediatamente do prazer e da dor. Na complexa relação entre impressões e ideias, é a paixão que se coloca como princípio da ação.

Se os seres humanos são dotados naturalmente de certas paixões, compreendidas como "existências originais", é preciso descrever como as ações, sentimentos e pensamentos se inserem e interagem no curso necessário do mundo. Hume pressupõe uma estrutura fixa de paixões (do mesmo modo como Schopenhauer ainda defende a fixidez das espécies).

A inserção da vontade e dos sentimentos morais nas paixões diretas é problemática na psicologia moral humiana, à medida que questionamos se há uma Natureza que simplesmente estabeleceu uma conexão entre nossas paixões e "certos fins objetivos"10, p. ex., a pressuposição de que há um altruísmo original e invariável no amor. O caráter desinteressado das paixões, do mesmo modo, é apenas pressuposto. Essa estrutura e configuração de paixões, pré-determinada pela natureza humana, excede os limites de uma psicologia moral naturalista.

A simpatia é determinante no mecanismo de associação das paixões. Apesar de não ser uma paixão, a simpatia (qualidade notável da natureza humana), possui importantes funções morais, que não foram consideradas por Paul Rée. Enquanto mecanismo,

10 Cf. a esse respeito, KEMP SMITH, Norman. The philosophy of David Hume. A critical study of its origins and central doctrines. Londres: Palgrave Macmillan, 2005, p. 142.

Cad. Nietzsche, Guarulhos/Porto Seguro, v.37, n.1, p. 71-87, 2016. | 75 
princípio de comunicação entre as paixões, a simpatia (simpathy) realiza a "conversão de uma ideia numa impressão, pela força da imaginação" "11. Ela não altera diretamente a força da paixão, pois isso depende do caráter do indivíduo e da posição e natureza do objeto. Mas é de fundamental importância para determinar o modo como as paixões calmas podem predominar sobre as paixões violentas, no Tratado da natureza humana. Ela é a fonte de apreço "por todas as virtudes artificiais"12. Novamente, esse "princípio muito poderoso da natureza humana ${ }^{13}$ " parece ser original, primário, sem história, produzindo "nosso sentimento de moralidade em todas as virtudes

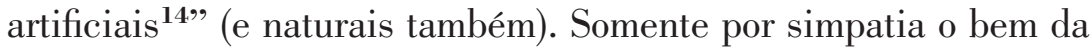
sociedade (alheio a nosso interesse) agrada.

Para Hume, originário é o princípio da simpatia, "que nos leva a sair de nós mesmos, e sentir o mesmo prazer ante os caracteres dos outros"15, úteis à sociedade. Rée, no entanto, procura naturalizar esse "sentimento de aprovação e desaprovação" (sentiment of approbation and blame) em relação aos dois tipos básicos de ações:

(1) As ações egoístas, nas quais o agente obtém seu bem-estar às cultas dos outros; e (2) as ações não egoístas, nas quais o agente, por vezes em detrimento de seu próprio bem-estar, busca o bemestar dos outros, ou abstém-se de causar danos em outras pessoas, para seu próprio bem ${ }^{\mathbf{1 6}}$.

A distinção bom - mau [gut - böse ] consiste unicamente nessa oposição entre ações egoístas, censuradas como moralmente más, e as ações não egoístas, sentidas como moralmente boas, por aqueles que foram beneficiados por sua utilidade. Nessa genealogia utilitarista,

11 HUME, David. A treatise of human nature. Op. cit., Livro II, Parte III, Seção 6, p. 302.

12 HUME, David. A treatise of human nature Op. cit., Livro III, Parte III, Seção I, p. 411 s.

13 "Simpathy is a very powerful principle in human nature".

14 "Our sentiment of morals in all the artificial virtues".

15 HUME, David. A Treatise of Human Nature. Op. cit., Livro III, Parte III, Seção I, p. 412 16 RÉE, P. Basic writings. Op. cit, p. 93.

76| Cad. Nietzsche, Guarulhos/Porto Seguro, v.37, n.1, p. 71-87, 2016. 
primeiramente foram censuradas ou elogiadas determinadas ações, conforme o dano ou utilidade que ocasionaram. Dos impulsos altruístas e egoístas que atuam efetivamente no ser humano, resultam ações (altruístas ou egoístas), que, posteriormente, foram ajuizadas como boas ou más ${ }^{17}$. Rée emprega o mecanismo de associação de ideias de Hume e a força do hábito para provar que houve um vínculo duradouro entre as ações boas e más e os respectivos juízos de bom e mau. $\mathrm{O}$ elogio [approbation] e a censura [blame], ao contrário de Hume, que os considerava "sentimentos naturais" [natural sentiments], constituem para Rée um processo de desenvolvimento e de transmissão cultural.

Os impulsos altruístas e egoístas são inatos (em sentido biológico darwinista). Entretanto, através da educação e dos hábitos adquiridos e herdados em meio à cultura em que cada um está inserido, surgiu um domínio valorativo, no qual as ações altruístas são sentidas e julgadas boas. Ressalto aqui a contribuição de Itaparica, ao diferenciar o aspecto biológico do altruísmo da atribuição valorativa que a ele fazemos. Nesse sentido, o senso da moralidade não é inato, mas é uma construção, uma convenção, uma "espécie de condicionamento realizado pelo elogio e pela censura"18. Desenvolvemos em nosso âmbito cultural o hábito de associar as ações altruístas aos impulsos não-egoístas, que eles nos parecem indissociáveis. É somente de modo convencional que a utilidade nos pareceu como o critério mais natural de valoração. Rée, que discutiu longamente com Nietzsche acerca da relação entre os impulsos (paixões) e os valores, abre uma brecha para as invectivas de Nietzsche contra a moral da compaixão e os impulsos altruístas. O altruísmo só se tornou um valor moral e uma virtude num certo estágio evolutivo da espécie humana, graças à seleção natural e à transmissão de características por meio de hábitos e costumes. Rée apoia-se em Darwin; Nietzsche, por sua vez, no "demônio do poder", pressupondo que nós podemos ser

17 Cf. ITAPARICA, A. L. M. Dissertatio. Op. cit., p. 63.

18 Cf. ITAPARICA, A. L. M. Dissertatio. Op. cit., p. 63. 
Araldi, C. L.

condicionados (não só externamente) a considerar o egoísta como bom.

Paul Rée concorda com o estabelecimento da lei efetiva da motivação, de Schopenhauer. Para provar que a "única motivação moral genuína" reside no altruísmo, o filósofo pessimista insere os seguintes pressupostos: 1) toda ação ocorre com um motivo suficiente para o caráter do agente; 2) o bem-estar e o mal-estar são os móveis da vontade; 3) toda ação refere-se a um ser com suscetibilidade para o bem-estar ou mal-estar: esse ser pode ser o próprio agente ou outro ser; 4) a ação egoísta é aquela "cujo fim último é o bem-estar e o mal-estar do próprio agente". Em decorrência disso, Schopenhauer afirma que o egoísmo e o valor moral de uma ação excluem-se um ao outro. Uma ação somente terá valor moral se não tiver nenhum motivo egoísta. Portanto, “a significação moral de uma ação só pode estar na sua relação com outros"19. Na ação justa e caritativa (compassiva) haveria um motivo completamente desinteressado, o bem-estar de um outro, o cuidado e a ajuda a um outro.

Se há vários pontos de contato na análise das ações e impulsos altruístas em Paul Rée, Hume e Schopenhauer, importa agora investigar como Nietzsche rompe com essas análises a partir de Humano, demasiado humano.

\section{Nietzsche: não há ações e impulsos altruístas}

Nietzsche concorda com Rée em vários momentos de sua abordagem da História dos sentimentos morais, no segundo capítulo de Humano, demasiado humano, p. ex. nos aforismos 35-37, 39 e 45 (MA I/HH I, KSA 2.57-59, 62, 67). Importa-nos aqui investigar as discordâncias em relação ao altruísmo. Com a arte da observação psicológica (dos moralistas franceses) e com os instrumentos de "dissecação psicológica" de que dispunha, Nietzsche pretende desenvolver a História dos sentimentos morais [die Geschichte der

19 SCHOPENHAUER, A. Sobre o fundamento da moral. São Paulo: Martins Fontes, 2001, p. 132.

78 Cad. Nietzsche, Guarulhos/Porto Seguro, v.37, n.1, p. 71-87, 2016. 
moralischen Empfindungen]. A defesa da existência de ações altruístas estaria baseada em análises errôneas. Até um certo ponto, a análise nietzschiana, com pretensões de ser verdadeira e efetiva, coincide com a de Rée. Assim ele define as quatro principais fases da história dos sentimentos morais até agora:

1) Primeiramente, as ações foram chamadas de boas e más, por suas consequências (úteis ou nocivas);

2) Em seguida, esquecemos a origem dessas designações, sem levar em conta as consequências. "Bom” e "mau', nessa etapa, são propriedades inerentes às ações;

3) Num terceiro momento, atribuímos as propriedades bom e mau aos motivos;

4) Por fim, atribuímos o predicado bom ou mau [gut oder böse] a todo o ser do homem, não somente a motivos isolados (cf. MA I/ HH I, 39, KSA 2.62).

A meta desse capítulo é restituir ao homem sua irresponsabilidade. Nesse aforismo, é dado um passo importante, à medida que o homem não é mais responsável pelos efeitos das ações, nem por suas ações, por seus motivos e pelo seu próprio ser. Nietzsche, que por essa época lia e discutia Lubbock com Rée, afirma que o homem se constitui a partir do influxo das "coisas passadas e presentes", mas não menciona Darwin ${ }^{20}$. Entendo que Nietzsche se esforça por delimitar as "fases da moralidade até agora", para propor, ele mesmo, uma guinada decisiva não só na filosofia moral, mas na própria história da moral. No aforismo 94 de Humano, demasiado humano I, ele afirma que até agora existiram três fases da moralidade. O animal só se tornou "homem" quando: i) busca a utilidade pessoal (a razão é um instrumento para isso); ii) ao agir pelo princípio da

20 A esse respeito, é significativa a análise de John Richardson: "Embora Nietzsche mencione Darwin apenas esporadicamente, e, em geral, apenas para repreendê-lo, seu pensamento é profunda e marcadamente darwiniano. Ele escreve à luz de Darwin, e depois dele, com uma persistência consciente do cenário evolutivo". RICHARDSON, J. "Nietzsche contra Darwin", Philosophy and Phenomenological Research, Vol. 65, No. 3 (Nov., 2002), p. 538. 
Araldi, C. L.

honra, o homem constitui-se como animal social, com sentimentos e deveres comuns. É o tempo do indivíduo coletivo [das collective Individuum]; por fim, iii) Nietzsche nomeia o grau mais elevado da moralidade [Moralität $]$ até sua época, o homem "age conforme a sua medida das coisas e dos homens, ele próprio define para si e para os outros o que honroso e útil; torna-se o legislador das opiniões, segundo a noção cada vez mais desenvolvida do útil e do honroso" (MA I/HH I, 94, KSA 2.91).

Essa terceira fase da moralidade, a "moral do indivíduo maduro", entra em conflito com as análises de Rée justamente em relação ao altruísmo. Tal moral afirma que em cada ação é preciso ter em vista o interesse pessoal, como seu bem supremo. O ponto fraco desse argumento, a recaída no âmbito das análises de Rée, é a afirmação utilitarista de que no interesse mais pessoal encontra-se a "maior utilidade para o conjunto" (MA I/HH I, 94, KSA 2.91). A guinada ocorre propriamente no parágrafo 96, quando Nietzsche define 'bom' como aquele que "obedece de bom grado ao que é moral", ou seja, aos costumes. "'Egoísta' e 'altruísta' não é a oposição fundamental que levou os homens à diferenciação entre moral e imoral, bom e mau, mas sim estar ligado a uma tradição, uma lei, ou desligar-se dela" (MA I/HH I, 96, KSA 2.92). São temas que serão desenvolvidos em Aurora (M/A, 9, obra em que Spencer ironicamente é um aliado de Nietzsche contra a hipótese psicológica de Rée). Entretanto, a análise dos hábitos, dos costumes e do prazer a eles ligados, marca a separação entre os dois pensadores. Eles permanecem ligados à noção de conhecimento libertador, ao projeto vago de construir modos de vida não morais, sem coação ou obrigação. Parece-me, já nesse momento, que o filósofo de espírito-livre não suporta nenhuma amizade, estelar ${ }^{21}$ ou terrena.

21 Acerca do desenvolvimento e da extinção lenta da "amizade estelar" entre Nietzsche e Paul Rée, confira SMALL, R. Nietzsche and Rée. A star friendship. Oxford: Oxford University Press, 2005.

80| Cad. Nietzsche, Guarulhos/Porto Seguro, v.37, n.1, p. 71-87, 2016. 
Nietzsche e Paul Rée: Acerca da existência de impulsos altruístas

\section{Prazer e instinto social}

O novo método de investigar os impulsos e as ações humanas, presente desde Humano, demasiado humano I (1878), está fortemente ligado às noções de prazer e desprazer [Lust und Unlust]. Nessa investigação de cunho preponderantemente psicológico, todas as ações individuais humanas teriam como meta o prazer e a fuga da dor. Não haveria uma distinção (moral) entre "boas" e "más" ações, pois todas elas são motivadas pela busca individual da obtenção e incremento do prazer: "Todas as 'más' ações são motivadas pelo impulso de conservação ou, mais exatamente, pelo propósito individual de buscar o prazer e evitar o desprazer" (MA I/HH I, 99, KSA 2.95).

Essa análise psicológica aparece articulada com considerações históricas, à medida que Nietzsche vincula a formação do sentimento moral com as sensações prazerosas que o indivíduo encontra em si mesmo, e com os novos tipos de prazer advindos da longa história da formação da sociabilidade. Foi sempre a busca obstinada de prazer que moveu os indivíduos a controlar as paixões próprias que poderiam impedir o acesso a novas fontes de prazer, à medida que suas paixões colidem com outras individualidades, com o mesmo objeto de desejo (p. ex., de uma propriedade). O "instinto social"22 surge como uma nova forma de prazer, adquirida com esforços contínuos e múltiplos. A ampliação do domínio das sensações de prazer decorrente das relações humanas tornou o homem "melhor" em relação ao estado natural pré-civilizatório. A segurança e o bem-estar em desfrutar prazeres comuns diminuíram a hostilidade "natural" entre os humanos, graças à ficção emergente da empatia.

22 Recordemos que para Rée, em Der Ursprung der moralischen Empfindungen, os instintos sociais são compreendidos de modo naturalista, a partir da teoria da seleção natural de Darwin. Esse impulso natural para cuidar dos outros somente se torna um fenômeno moral no mundo humano. Assim se explicariam as sensações prazerosas concomitantes às ações altruístas (RÉE, P. Der Ursprung der moralischen Empfindungen. In Gesammelte Werke (1875-1885). Org. por Hubert Treiber. Berlim: de Gruyter, 2004, p. 131 s. 
Araldi, C. L.

As manifestações de prazer semelhantes despertam a fantasia da empatia [Phantasie der Mitempfindung], o sentimento de ser igual: o mesmo fazem os sofrimentos comuns, as mesmas tormentas, os mesmos perigos e inimigos. Com base nisso se constrói depois a mais antiga aliança: cujo sentido é defender-se e eliminar conjuntamente um desprazer ameaçador, em proveito de cada indivíduo. E assim o instinto social nasce do prazer (MA/ HH I, 98, KSA 2.95).

O que conta nessa perspectiva filosófica é a manutenção e o incremento do poder do indivíduo. Tanto no estado anterior à sociabilidade quanto na história da moralização. Nas presumíveis ações "más", que teriam como meta o sofrimento alheio, e nas ações compassivas, que, ao contrário visam o bem do outro (na diminuição de seu sofrimento), estão em jogo apenas diversos elementos de prazer pessoal, que no fundo expressam o prazer do exercício do poder, da superioridade em relação ao que sofre. Ser causa do sofrimento do outro ou querer aliviar sua dor seriam formas de ações egoístas (cf. MA I/ HH I, 103, KSA 2.99).

O sentimento da simpatia, nessa perspectiva, não é natural. Natural é o temor e antipatia em relação ao estranho (cf. Nachlass/ FP 1880, 4[123] KSA 9.132). Esse sentimento dificilmente ocorria nos tempos selvagens e guerreiros. Assim, o medo é o pai da moral. $\mathrm{O}$ medo ante o incerto, ante outros homens, ante a natureza, fez com que o homem primitivo (sem discernimento da "causalidade efetiva") se submetesse a regras de uma autoridade superior. O filósofo solitário opera com as noções de sentimento de poder [Gefühl der Macht] em 1877, de prazer no poder, de medo [Furcht] e vontade de potência [Wille zur Macht] em sua hipótese pré-genealógica. O prazer no poder decorre sempre do desprazer na impotência [Unlust an der Ohnmacht]. O vínculo dos sentimentos morais com a sociabilidade é determinante, devido à alta estima dos seres humanos pela opinião dos outros. Em relação à vaidade, percebe-se a influência de Rée na filosofia do espírito livre. Entretanto, ao operar com a noção de medo 
como base naturalista da vida do homem primitivo, Nietzsche se distancia de Rée, e valoriza mais a hipótese genealógico-psicológica de Herbert Spencer acerca da origem da moral.

Nietzsche ressalta o caráter egoísta das paixões para, no final do segundo capítulo de Humano, demasiado humano I, afirmar a inocência e irresponsabilidade do homem na corrente do mundo: " $O$ egoísmo não é mau, porque a ideia de 'próximo' [...] é muito fraca em nós [...]. Saber que o outro sofre é algo que se aprende, e que nunca pode ser aprendido inteiramente". Tanto a maldade quanto à ação compassiva seriam formas de fruição de si mesmo (MA I/HH I, 103, KSA 2.99). O que há de mais oposto a Rée e a Schopenhauer do que afirmar que a maldade não visa ao sofrimento alheio, e que a compaixão não intenta o bem do outro?

A coerção do indivíduo coletivo sobre os seres humanos individualizados é vista como necessária para o surgimento da moralidade (cf. MA I/HH I, 99, KSA 2.95). O processo da eticidade [Sittlichkeit] opera uma transformação radical, à medida que a coerção se torna costume. A força do hábito e dos costumes tornaria prazerosa a prática de ações, que bem mais tarde passam a ser chamadas de "morais". O caráter ético [sittlich] de uma ação, desse modo, é constituído pelo efeito prazeroso dos costumes. Nietzsche, entretanto, diz que o hábito, por ser um gênero de prazer, é "fonte da moralidade" [Quelle der Moralität]. Hábitos praticados de bom grado não são apenas agradáveis, mas também úteis. Assim, após muitas repetições, os hábitos que valem para os indivíduos como sua única condição de existência são adotados por uma comunidade ou povo, constituindo sua eticidade (cf. MA I/HH I, 97, KSA 2.94).

É no indivíduo, contudo, que os hábitos (ligados a costumes legitimados socialmente) prazerosos serão sentidos como morais. É o sentimento, potencializado pela apreciação e valoração subjetivas das ações prazerosas, que engendra o caráter moral das mesmas. Na abordagem histórico-psicológica nietzschiana não há observação 
Araldi, C. L.

ou perspectiva da terceira pessoa, ou de um espectador judicioso. Nesse ponto já nos deparamos com a interrogação: esse processo denota um domínio moral objetivo das ações ou é somente um âmbito valorativo, próprio de um indivíduo que estima e interpreta seguindo convenções socialmente aceitas? Por se sentir valioso e vinculado a uma comunidade, o indivíduo decidiria espontaneamente obedecer aos valores e às leis de uma comunidade moral. $\mathrm{O}$ prazer no costume constituiria uma espécie de segunda natureza, noção pouco desenvolvida no período intermediário, apesar de sua importância. Longe de defender um cirenaísmo na ética, o autor de Humano, demasiado humano pretende atingir formas mais elevadas, mais sutis e mais espirituais de prazer. O prazer, especialmente o prazer no exercício do poder, é o critério para a valoração das ações. Prazer não é entendido nesse contexto como um mero epifenômeno dos impulsos; ele não é um sentimento ou uma sensação decorrente, mas está intrinsecamente ligado aos impulsos naturais, originais, dominadores e expansivos do homo natura.

Os sentimentos morais são vistos como expressões de desejos de exercer poder sobre outros. Fazer bem e mal a outros são formas de exercer o poder sobre eles. Na obra que encerra o período da filosofia do espírito livre, A gaia ciência, o filósofo solitário propõe uma "teoria do sentimento de poder", na qual dor e prazer são instrumentos para aumentar o poder (cf. $F W / G C, 13$, KSA 3.384). Não encontramos ali, contudo, a pedra de toque do pensamento ético nietzschiano. Essa psicologia dos impulsos morais não expõe como surgem os valores a partir das avaliações e formas de vida. Tudo dependeria apenas de como o indivíduo "tempera a sua vida". Ou seja, é uma questão de gosto, do temperamento de indivíduos, tanto dos nobres quanto dos compassivos (no deleite com suas próprias ações belas). Dos sentimentos de dor e prazer não se depreendem naturalmente valores e virtudes tipicamente morais. No parágrafo 107 de Humano, demasiado humano, Nietzsche se atém ao "desejo de autofruição 
do indivíduo", que seria o motivo de todas as ações humanas. Essa busca de prazer não guia ao âmbito moral, uma vez que invalida uma separação entre boas e más ações. Com Rée, Nietzsche propõe uma transmutação da humanidade: da humanidade moral em sábia. Alguns raros e enobrecidos homens, no entanto, poderiam conquistar a liberdade de espírito - para estabelecer novos hábitos e por eles serem regidos. Mas esse seria um lento processo de milênios, sob o sol do conhecimento purificador das ciências naturais e da gaia ciência de Nietzsche. Em nosso incipiente e confuso século XXI, contudo, não vemos nada parecido como uma humanidade mais sábia!

A vontade de potência [der Wille zur Macht] servirá aos propósitos de Nietzsche, de provar que o "demônio do poder", o sentimento de poder, impulsiona todas as ações humanas, desenvolvendo (ampliando e 'fantasiando') a abordagem psicológica de La Rochefoucauld e de Helvétius. Rée possui um programa naturalista mais estruturado, posicionando-se claramente em relação a Schopenhauer, a Hume e a Helvétius, procurando desenvolver a teoria da evolução de Darwin numa perspectiva teórico-moral. Podemos perceber o difícil distanciamento de Nietzsche em relação a Schopenhauer, que é transposto num "diálogo de mortos-vivos". O entusiasmo de Nietzsche pelas ciências naturais decanta-se num naturalismo sui generis, em que a necessidade dos métodos rigorosos das ciências não serve ao conhecimento (descrição) da natureza humana, mas sim à arte de viver do espírito livre. Nietzsche tem enormes dificuldades em transpor as propriedades dos impulsos e instintos puramente naturais para o âmbito dos valores. Contrapondo-se decididamente a Paul Rée, ele esforça-se por negar a existência de qualquer impulso altruísta. Se a qualidade que distingue e vige em tudo o que vive, sente e quer é a intensificação do poder, então não há espaço para a compaixão, para a benevolência e para o altruísmo. Quanto mais avança em sua valorização do poder, parece que Nietzsche se afasta sempre mais da tarefa empírica de naturalizar a moral. Isso porque ele precisa 
Araldi, C. L.

'antropomorfizar' a natureza, de modo a projetar e a salvaguardar nela o "sentimento do poder".

\begin{abstract}
This article investigates the disagreement between Nietzsche and Paul Rée on the existence or not of altruistic drives in humans. Paul Rée, in The Origin of the Moral Feelings (Der Ursprung der moralischen Empfindugen), posits the existence of both egoistic and altruistic drives in human beings. From Darwin's theory of evolution, he develops an evolutionistic moral psychology, emphasizing the naturalistic character of altruistic attitudes. Nietzsche's critiques on the altruistic mode of valuing since Human, All Too Human will be analyzed, having in mind his discussion with Paul Rée on the status of habit, costumes and motives of action. The new way of considering pleasure, mainly in the intensification of the feeling of power, marks a new orientation on the origin and development of moral feelings, in which egoism has a central place.
\end{abstract}

KeyWords: drives - egoism - altruism - pleasure - feelings - morals

\title{
Referências bibliográficas
}

HUME, D. Tratado da natureza humana. 2. ed. São Paulo: Ed. UNESP, 2009. . A Treatise of Human Nature. New York: Dove Publications, 2003.

ITAPARICA, A. L. "Nietzsche e P. Rée. O projeto de naturalização da moral em Humano, demasiado Humano". Pelotas, Dissertatio, no. 38, 2013, p. 57 -77.

JANAWAY, Christopher. Beyond Selflessness: Reading Nietzsche’s Genealogy. New York: Oxford University Press, 2007.

KEMP SMITH, Norman. The Philosophy of David Hume. A critical study of its origins and central doctrines. Londres: Palgrave Macmillan, 2005.

NIETZSCHE, F. W. Sämtliche Werke. Kritische Studienausgabe (KSA). 15 vols. Organizada por Giorgio Colli e Mazzino Montinari. Berlim: de Gruyter, 1988.

86 | Cad. Nietzsche, Guarulhos/Porto Seguro, v.37, n.1, p. 71-87, 2016. 
Nietzsche e Paul Rée: Acerca da existência de impulsos altruístas

RÉE, Paul. Basic Writings. Translated and edited by Robin Small. Urbana, Chicago: University of Illinois Press, 2003.

RÉE, Paul. Gesammelte Werke (1875-1885). Org. por Hubert Treiber. Berlim: de Gruyter, 2004.

RICHARDSON, J. “Nietzsche contra Darwin”, Philosophy and Phenomenological Research, Vol. 65, No. 3, Nov., 2002, p. 537-559.

SALANSKIS, E. "Moralistes darwiniens: les psychologies évolutionnistes de Nietzsche et Paul Rée". Nietzsche-Studien, vol. 42, Berlim: de Gruyter, 2013, p. 44-66.

SCHOPENHAUER, A. Sobre o fundamento da moral. São Paulo: Martins Fontes, 2001.

SMALL, R. Nietzsche and Rée. A Star Friendship. Oxford: Oxford University Press, 2005.

Artigo recebido para publicação em 15/09/2015.

Artigo aceito para publicação em 11/11/2015. 